\title{
Impact of Climate Change on Migration from Vietnam to Russia as a Factor of Transformation of Geopolitical Relations
}

Elena E. Pismennaya

Finance Academy under the Government of the Russian Federation, Moscow, Russia

Irina S. Karabulatova

Institute of Socio-Political Research of the Russian Academy of Sciences, Moscow, Russia

Sergey V. Ryazantsev

Institute of Socio-Political Research of the Russian Academy of Sciences, Moscow, Russia

Artem S. Luk'yanets

Russian State Social University, Moscow, Russia Email: radogost2000@mail.ru, riazan@mail.ru

Roman V. Manshin

Center of social Demography and Economic Sociology at the Institute of Social and Political Research of the Russian Academy of Sciences, Moscow, Russia

Doi:10.5901/mjss.2015.v6n3s2p202

\section{Abstract}

The article gives a brief description of the migration from Vietnam to Russia. The place of migration from Vietnam in global migration turnover is represented, as well as historical forms of migration and the relationship between Vietnam and the Soviet Union on the one hand, and later Russia, on the other hand. As a result of climate change on the planet Vietnam faced with new challenges and threats. Geographical position peculiarity, relief and demographic potential of the territory led to the need of revision of the existing and well-established policy of resettlement of the population across the country. Speaking of global climate change on our planet, one implies the average temperature of the environment increase, including the temperature of the water of the World Ocean. This given phenomenon is also denoted as the term "global warming". Negative phenomena, frequent due to climate change, in the medium term outlook will require the development of a new concept of migration policy in Vietnam, mostly aimed at the resettlement of people from potentially dangerous places of residence, primarily coastal areas. When considering the stated problem, the authors show the gradation of concepts like "climate migrants", "environmental migrants", "environmental refugee". In implementing the most unfavorable forecasts, the country will face the need of resettlement of millions of people. In the conditions of the limited area of the country thousands of people will be looking for a new place of residence outside the country.

Keywords: global climate change, natural phenomena, migration policy, climate migration, resettlement of the population.

\section{Introduction}

No scientist, professor and just sane person would dispute the fact that humanity depends on the surrounding nature. Despite the fact that the strength of this relationship is different, the economic activity pursued by the nations of the Earth during the history of its existence, has been closely associated with the climate and landscape of inhabited areas. Dutch researchers under the direction of Isla Castaneda from the Royal Netherlands Institute for Sea Research (TNIOZ) and her German colleagues from the University of Bremen presented new evidence of the influence of climatic sudden changes in the Sahara on early human migration to the scientific community.

Today the problem of so-called climate migration (i. e. population migration due to climate change) which is a specific kind of ecological migration - flows of people, the movement of which is due to environmental causes, is of 
particular urgency. It is estimated that in 2010 there were an estimated from 30 to 60 million environmental migrants, including environmental refugees, and by 2050 their number may reach 200-250 million. This rapid growth is not the last to be associated with the effects of climate change, especially with the more devastating natural phenomena of hydrometeorological character (Kattsov, V.M., Kobysheva N.V., Myaleshka V.P. and others, http://eknigi.org/ estestvennye_nauki/152577-ocenka-makroyekonomicheskix-posledstvij-izmenenij.html, 2011).

Climate emigration from Russia in the foreseeable future is improbable or negligible, and in any case it will not have a significant impact on the socio-demographic situation in the country and abroad. That seems to be a vivid manifestation of the higher (compared to many other regions of the world) adaptive capacity of Russia, which has been appropriate referred to the important advantage of the country by national Climate doctrine. Russia's geopolitical concept of development is a fundamental document defining the goals and objectives of the Russian Federation in the long historical perspective, principles, methods and ways of geopolitical activity of the society as a whole. A distinctive feature of the current historical moment is the transition from the ideological confrontation to the confrontation of civilizations, with a leading contemporary confrontation between the Western (Euro-American) civilization on the one hand, and Islamic, Orthodox and Confucian (China) civilizations - on the other.

In this context, perspectives of climate immigration to Russia is represented in different way for tens of millions, and possibly hundreds of millions of people abroad, primarily from Africa and Asia, who will be forced to leave their homes due to the effects of climate change, including natural or man-made disasters. Modern Russian geopolitical strategy includes two aspects: Eurasian geopolitical axis consolidation around Russia with breakthroughs in some areas through an intermediate geopolitical region (Rimland) for properly geopolitical maritime civilization to create in these areas the threat of a structural subdivision of the Atlantic block (Concept of geo-political development of the Russian Federation for the period up to 2050, http://do.gendocs.ru/docs/index-215602.html). In the "Concept of Russian Federation geopolitical development for the period up to 2050 " it is indicated that the main geopolitical allies of Russia are the countries of continental orientation, seeking to build a multipolar world and built on the basis of ideological and religious systems of communal orientation, suggesting the power of ideas dominance in the organization of society (Orthodoxy, Islam and various models corresponding secular ideologies). The developers of the "Concept ..." are among the allied states of the near abroad - the former Soviet republics, the traditional allies of the USSR-Russia in the Arab world and in the Balkans, Cuba, India and China, as well as Greece, which, in spite of NATO membership, is an Orthodox country, which was demonstrated in its position on the war against Yugoslavia. At the same time the potential geopolitical allies of Russia are countries due to their geopolitical position and national traditions of the "continentalist" peoples and historical circumstances are included in the Atlantic block and are its allies. Those are, above all, Germany and Japan ) Concept of geo-political development of the Russian Federation for the period up to 2050, http://do.gendocs .ru/docs/index-215602.html). In this regard, it seems justified to include in the list of countries-geopolitical allies and / or partners the countries which, because of climate change, will be forced to migrate from their country in large quantities. Vietnam, in our opinion, refers to those countries.

On the one hand, Vietnam is an active member of international migration as a donor country. In 2010 the absolute number of emigrants Vietnam ranked twenty-third place in the world. In 2010 there were more than 2.2 million Vietnamese citizens outside the country, which came to $2.5 \%$ of the population. The main countries of Vietnamese migrants destination were economically developed countries such as the USA, Japan, Australia, Canada, Germany, France, South Korea, United Kingdom, as well as neighboring Cambodia and Thailand. In terms of the volume of remittances received from abroad (more than 7.2 billion USD) Vietnam held the sixteenth place in the world (Migration and Remittances Factbook 2011. The World Bank, 2011).

On the other hand, global warming so attacks the land of Vietnam that climatologists say about the imminent submergence of Vietnamese lands. Thus, in 2013 there were powerful heavy rains in Central Vietnam, which this small country has not observed for 14 years. According to environmentalists, the most difficult situation is Quang Nam Province: about 65,000 of its inhabitants were removed from their homes and migrated to other places (Imperial city of Vietnam goes under water, 2013, http://ecoportal.su/news.php?id=74805). Vietnamese tourism industry representatives are concerned with the destruction of the Hoi An city coastline, which is caused by rising sea levels and changes in the delta of the Thu Bon River, which flows through the city. Erosion threatens to destroy the famous beaches, which are the heritage of the ancient city, along with its rich historical heritage. Dozens of resorts threaten to submerge into the sea in the near future. The climate - is the main component of nature that determines the possibility of tourism development in any country. The situation has dramatically changed over the past two decades. This is particularly evident by the example of the famous Cua Dai Beach which is in $5 \mathrm{~km}$ away from Hoi An. Even 10 years ago its width was 200 meters and today it has narrowed to 40 meters. The rest of the beach has plunged into the water. Erosion has made the sea come closer to the 1.5-kilometer stretch of road connecting the beach with Hoi An. During the storm waves reach it and 
destroy the pavement (Vietnam Beaches are covered with water, http://www.poedem.ru/news/151168/). In this regard, the acute question of salvation and preservation of the unique Vietnamese ethnic group and its culture, which is also experiencing internal affection towards Russia and the Russian people, comes up.

For Russia Vietnam is quite an important migration partner since Soviet times. Currently Vietnamese citizens' trips to Russia are carried out on the basis of the Agreement between the Government of the Russian Federation and the Government of the Socialist Republic of Vietnam signed in Moscow on terms of mutual trips of citizens, October 28, 1993. In accordance with this agreement, Vietnamese citizens enter the Russian Federation by visas. Most Vietnamese enters the Russian territory through airports (96\%). At present time air communication between a number of cities in Russia with Hanoi and Ho Chi Minh is established. The largest air carriers along here are the "Aeroflot" and "Vietnam Airlines". In the overall structure of migration from Vietnam to Russia travel on business (61\%) and private businesses (22\%), as well as transit to a third country (about 10\%) are dominated.

In 2012 the Russian Federal Migration Service has issued only 12 thousand work permits for Vietnamese in Russia (Labor and Employment in Russia - 2013, 2014), although the Russian economy could more actively employ Vietnamese workers and experts. All the more there are Soviet times test cases. According to the 2010 Census of enumeration, the number of Vietnamese in Russia amounted to 14 thousand people (almost 2 times less than in the 2002 Census). Considering undocumented migrants one can, of course, assume that the number of Vietnamese somewhat higher than the official figures. Previously, we have evaluated this amount at the level of 100-150 thousand men. Mainly Vietnamese study, work in trade, agriculture, restaurant business, manufacturing sector employment is increasing. However, most likely, the recent hardening of Russia's migration policy, which has resulted involuntarily difficulties for Vietnamese migrants (for example, after the events in Biryulyovo), gradually reduce the number of Vietnamese migrants. Unfortunately, sometimes the bodies of migration control and police in Russia deny the humane treatment of the Vietnamese migrants.

\section{Materials and Methods}

Most researchers in this country and abroad estimate the future state of the climate to be warmer than today, i.e. the increase in average global temperature during the XXI century is expected (Smarter, C., 2012). The basis for such scenarios is related to human activity, which leads to the increase of concentrations of greenhouse gases, primarily monoxide carbon, in the atmosphere (Smarter, C., 2012), which is particularly reflected in the temperature regime of Vietnam, where the average annual temperature in the last 50 years has increased by about $0,5-0.7$ degrees centigrade (Pham, Khoi Nguyen, 2009). According to the Estimations of very famous Intergovernmental Commission on Climate Change, the global average temperature for the XXI century will rise from 1.5 to 5.5 degrees. However, a number of researchers, evaluating the dynamics of the climate with their scientific ideology, believe that in the 20es of this century it will begin cooling. But such researchers are of minority. Now for most scientists the question is following: what do human activities contribute to the process of global temperature increasing? After all a natural climate variability is existing. Many experts believe that it is central in the process of global temperature increase (Vilfand, R., 2007, http://ria.ru/online/20070227/61308092.html\#ixzz3SdF3bonv). In climate and weather characteristic one should pay attention to a number of theses (aspects). Firstly, the climate and the weather - are different notions, which are interpreted as synonymous by the social consciousness, although this is not so, at that the climate - is more general notion than the weather. Therefore, the characterization should be started with a study of the basic laws and concepts of climate change, considering the main elements, events and indicators that characterize them sequentially. First of all, one should pay attention to climatic zone (zones) in which a country is located, and what are the characteristics of their spread on the territory. If there are several climatic zones on the territory of a country, it is advisable to choose the most favorable for tourism and begin to characterize this zone according to the following plan: the type or types of climate, as if the name of the zone has the "sub" prefix, the types of climate change on the seasons of the year according to types of air masses. Climatic conditions vary within the zone from west to east, according to subtypes of air masses changes climate areas change too. The type of climate depends on the type of air mass, and climatic region - on the subtype of air mass. Information about what climatic region is the region of interest is obligatory, since climatic indicators and especially weather data directly depend on it. Then it is necessary to consistently identify the main elements: data on temperature, pressure, humidity, precipitation, wind. Indicators parameters during the year, on average per year, seasonal and oscillation amplitude changes are considered. The amplitudes are important in determining the specific characteristics of the climate. Thus, for example, significant oscillation frequencies are typical for the areas with continental and sharply continental climate, and in the coastal areas oscillation frequencies are small. Characteristic of all climate indicators one should check at the main seasons. 
The sequence is similar to the climate characteristics: type of weather, characteristic of the basic elements and phenomena. The only difference is that when weather characteristics qualitative indicators, as a rule, play more significant role, forming the image of the sojourn environment (Method for studying climate, http://preventionweb. net/go/11348; Climate change, 2009).

These parameters are discussed in the context of the migration behavior of the local population and provide a basis for predicting the vitality of settlements in some areas (Karabulatova, I.S., 2008; and Shirin, S.S., Bogolubova N.M., and Nikolaeva J.V., 2014).

The research is synergistic and comparative one, where climatology and geography data are compared with authors own empirical researches in Vietnam with accordance to migrate intentions of Vietnamese themselves being situated at the epicenter of climate changes in general. The territory of the possible threats is not limited to the provinces of the Mekong Delta. Thus, in a number of central coastal provinces, constantly suffering from the cyclones and typhoons, these natural phenomenon have been increasing. In November 2013 several provinces in Central Vietnam suffered from the Philippines typhoon "Haiyang", which caused unprecedented flooding of a number of coastal villages and small towns, significant economic damage and people killing.

Materials for the study is based on research reports of the Institute of Strategy and Policy on Natural Resources and Environment of Vietnam, as well as the data of opinion polls conducted personally by the authors during the 20122015 years.

\section{Results}

The nature of the Vietnamese migration earlier was due to socio-economic factors. Historically, one of the regions of the resettlement of Vietnamese migrants have also become countries of Eastern Europe and the former Soviet Union. Educational migration had occupied a special place, labor migration - more recently. According to the Organization for Economic Cooperation and Development (OECD) and national statistics, it was found that the number of Vietnamese in Eastern Europe (excluding the Russian Federation) may be about 100 thousand men. The Czech Republic is home to about 70 thousand, Poland - 10 thousand, Austria - 7 thousand, Hungary - 5 thousand, Slovakia - about 3 thousand, Bulgaria - about 1 thousand Vietnamese. There are no exact figures on the number of Vietnamese people in Russia and the CIS countries. According to rough estimates in all the republics of the former USSR there are no less than 350-400 thousand men. However, climate change in the long term will lead to a significant transformation of global migration flows. According to the 2002 census, there were 26 thousand Vietnamese living in Russia, and on the basis of the census of 2010 their number had decreased to 14 thousand men. Although this figure is actually much higher and, according to our estimates, up to 100-150 thousand men.

According to the International Organization for Migration, in the next 40 years the average global temperature will increase by 2-5 degrees, migration flows of climate migrants at the same time can be from 25 million to 1 billion. (Migration, Environment and Climate Change: Assessing the evidence, http://publications.iom.int/bookstore/free/ migration_and_environment.pdf). A feature of this type of migration in the medium and long term is in its international character, in respect of crossing state borders. In the short term flows of forced climate migrants are likely to be able to fully distributed within the national borders of their countries without a strongly pronounced international orientation. However, in the long term a number of countries, particularly island ones, will be faced with acute overcrowding of the remaining areas and, as a result, flows of climate migrants will go beyond the country of permanent residence. At the same time, Vietnam became attractive to the Russians in respect of migration because of its cheap life and warm climate. The so-called Russians' downshifting acquired in Vietnam similarities with downshifting in India (Goa) and Thailand (Pattaya, Phuket).

Vietnam is among the five countries which are most vulnerable to the rise of the water level in the World Ocean due to global warming. The area of potential flooding includes most populous and economically important territories for Vietnam.

According to preliminary data from our research, which is largely correlated with the data of climate scientists from Vietnam, now the permanent flooding areas are inhabited by more than 5.5 million people living in five provinces of the Mekong Delta and Ho Chi Minh City, which, from the legal standpoint, refers to south-western region of the country (Tran, Hong Viet, http://vietnam.um.dk/en/danida-en/climate-change-initiatives).

A vital problem for Vietnam is a significant discrepancy between the population of Vietnam and the size of areas which are suitable for human habitation. Over the last five years in some places due to river flooding entire streets in the villages are being destroyed. So in 2010 in the district Namkhan province Kamau 20 meters river bank has collapsed, killing people and destroying houses. According to local residents, such cases began to occur only in the last 10 years. 
The only way, which is used by the Vietnamese Government and the people themselves, is to construct new dams and weirs, as well as strengthen existing ones. But every year more and more people realize that this mechanism has small positive effect. A strong tropical storm can inflict significant damage to dams, which one has to build and strengthen again.

As a result of the 2014 survey of people living in the Mekong Delta, it is ascertained that $95 \%$ of respondents surveyed had faced difficulties or problems caused by climate change. Of these, $58 \%$ of respondents pointed to the floods, $13 \%$ typhoons and tsunamis. The main negative consequences, it was stated yield reduction - $57 \%$, flooding (underflooding) houses - $28 \%$, physical injury - $4 \%$, death - $1 \%$. $73 \%$ of respondents are ready to leave their place of permanent residence.

\section{Discussion}

Despite the importance and significance of the problem analyzed, currently in the scientific community a terminological system has not yet developed. That creates certain difficulties for a theoretical-methodological as well as empirical part of science. At the same time, climatic and ecological situation in Vietnam is widely represented in the literature (Ryazantsev, S.V., Luk'yanets A.S. and Nguyen Canh Toan, 2013; Doyle, T.W., Day R.H. and Michot T.C., 2010; Kuznetsov, N.G. and Ryazantsev S.V., 2011; Shirin, S.S., 2015; Hiroshi, Takagi, Miguel Esteban and Nguyen Danh Thao, 2014; Ha Thi Quynh Nga, http://www.fes-sustainability.org/en/nachhaltigkeit-und-demokratie/climate-change-and-energy-vietnam, 2014). Bach Tan Sinh indicates that the Vietnamese government is trying to carry out systematic work on climate change and reduce land flooding, but these measures have not yet given a proper result (Bach, Tan Sinh, http://www.climateadapt. asia/upload/publications/files/4d4620457c5b1Vietnam.pdf., 2010). Chris Rose points out that "While there is scope for climate migrants to be accepted under this existing framework of law, greater clarity and certainty could be provided by creating a new immigration class of 'climate migrant' along with targets and programs to ensure Canada lives up to its moral responsibilities" (Chris, Rose, http://www.desmogblog.com/2014/11/10/new-report-urges-canada-prepare-climatemigrants-warming-world-ccpa, 2014). This position excellently emphasizes the importance of this category of migrants in the modern world of global warming. However, the very category of climate migrants has no definition in scientific analytical literature.

Today one can say that in the theoretical scientific knowledge there is no absolutely clear and distinct interpretation of the concept of how one should call the category of migrants, who were involved in migration processes under the influence of climate change. Analyzing the available scientific work, it can be concluded that this aspect is often solely in the plane of scientific perception of each individual scientist which is active in this field. Thus, the designation category of migrants, depending on the nature and focus of the research, one defines as: "environmental migrants", "environmental refugees", "climate migrants", "climate refugees". There is no consensus on the interpretation of the "climate" or "ecological", and even more on the interpretation of the "migrant" or "refugee". In the English-speaking academic environment this notion is called «environment migration», and therefore the people involved in this type of migration «environmental migrants», or «environmental refugees», literally - ecological refugees (Piguet, E., Pecku A., and P. De Gyuktener, 2013).

In our opinion, these are two different, though similar, categories of migrants, as opposed to foreign scientific thought, where often those two definitions are often treated as synonyms. In our opinion, the term "climate" and "environmental" migrants are not synonymous, since the first concept focuses precisely on natural factors of migration, and in the second case the migration can be caused by environmental pollution, due to an accident at the nuclear power plant, chemical plant, etc. Likewise, you can divide the concept of "migrant" and "refugee". If in case of certain climatic and weather conditions there is a threat of death or health occurs, and one is forced to leave its place of permanent residence, it can certainly be attributed to the category of "refugee". At the same time, if a person has decided to change its place of residence due to changes in mean annual temperature, decrease or increase the norms of annual precipitation that is not a direct threat to human life and health, it is correct to identify such people with the term "migrant", not a "refugee".

Second, the specifics feature of the research on this issue is the lack of specific, real-world examples. This largely explains the insufficient knowledge about the impact of climatic factors on the migration purposes and processes.

\section{Conclusion}

Climate change in the long term will lead to a significant transformation of global migration flows. According to the International Organization for Migration, in the next 40 years the average global temperature will increase by $2-5$ degrees, migration flows of climate migrants at the same time can total from 25 million to 1 billion men (Migration, Environment and 
Climate Change ..., http://publications.iom.int/bookstore/free/migration_and_environment.pdf, 2009). A feature of this type of migration in the medium and long term is its international character, in respect of crossing state borders. In the short term flows of forced climate migrants are likely to be able to fully distributed within the national borders of their countries without a strongly pronounced international orientation. However, in the long term a number of countries, particularly island ones, will be faced with acute overcrowding of the remaining areas and, as a result, flows of climate migrants will go beyond the country of permanent residence.

According to the 2002 census, 26 thousand of Vietnamese were living in Russia, and on the basis of the census of 2010 their number decreased to 14 thousand men. Although this figure is actually much higher and, according to our estimates, up to 100-150 thousand men.

Currently, the majority of Vietnamese lives and works in Moscow, Stavropol region, Bashkortostan, Volgograd, Sverdlovsk, Khabarovsk Territory and other regions of Russia. In Russia there are newspapers and magazines in Vietnamese, Vietnamese satellite channel television. In general, the Vietnamese working in trade, agriculture, restaurant business, industrial sector, a lot of Vietnamese students are studying in Russian universities. Most of Vietnamese workers and students in Russia have come from North Vietnam.

\section{Acknowledgement}

The article prepared within the RFBR grant, № 15-06-02854, "Economic-mathematical modeling of social reserves Russia's demographic development: a systems approach." And RHF grant, project № 13-22-09001 "The demographic and socio-economic impacts of flooding of coastal regions of Vietnam in terms of global warming, 2013-2015"

\section{References}

Bach, Tan Sinh, 2010. The Scoping Assessment on Climate Change Adaptation in Vietnam. Summary was conducted and written in 2010. Bangkok, Thailand. 30 pp. http://www.climateadapt.asia/upload/publications/files/4d4620457c5b1Vietnam.pdf.

Vilfand, R., 2007. Methods of meteorological research and weather forecasting, the Internet - a source access mode: RIA Novosti http://ria.ru/online/20070227/61308092.html\#ixzz3SdF3bonv.

Climate change, Sea level rise scenarios for Vietnam, Ministry of Natural Resources and Environment (MONRE), Viet Nam, 2009 (http://preventionweb.net/go/11348).

Shirin, S.S., 2015. Corruption in higher education in Russia - First decade of the 21st century International Education Studies, 8 (2), 160-168 pp.

Doyle, T.W., Day R.H. and Michot T.C., 2010. Development of sea level rise scenarios for climate change assessments of the Mekong Delta, Vietnam, US Geological Survey, Open-File. Report 2010-1165 pp.

Shirin, S.S., Bogolubova N.M., and Nikolaeva J.V., 2014. Application of David Easton's model of political system to the world wide web Sergey Sergeevich Shirin. World Applied Sciences Journal, 30 (8), 1083-1087 pp.

Migration, Environment and Climate Change: Assessing the evidence / International Organization for Migration (IOM), Geneva, 2009. http://publications.iom.int/bookstore/free/migration_and_environment.pdf. Date of access: 21.02.2015.

Imperial city of Vietnam goes under water, 2013 , the Internet source, on line publication date 18.11.2013, access mode: http://ecoportal.su/news.php?id=74805, date of access: 24.02.2015.

Karabulatova, I.S., 2008. Prognostic toponymy: the transformation of the toponymy of space in language consciousness of Russian speakers. Tyumen: Pechatnik. $254 \mathrm{pp}$.

Kattsov, V.M., Kobysheva N.V., Myaleshka V.P. and others, 2011. Estimation of the macroeconomic impact of climate change on the territory of the Russian Federation for the period up to 2030 and future trends. M., 2011, electronic source, http://eknigi. org/estestvennye_nauki/152577-ocenkamakroyekonomicheskix-posledstvij-izmenenij.html. Date of access: 24.02.2015.

Concept of geo-political development of the Russian Federation for the period up to 2050, the Internet source, access mode: http://do.gendocs.ru/docs/index-215602.html, date of access 24.02.2015.

Kuznetsov, N.G. and Ryazantsev S.V., 2011.. How to use the Russian migration potential of Vietnam (article, part 1). In the: Asia and Africa today, \# 6 , Moscow. 36-42 pp.

Migration and Remittances Factbook 2011. The World Bank. 3, 13, 257 pp.

Piguet, E., Pecku A., and P. De Gyuktener, 2013. Population migration and climate change. In the: Geography and Natural Resources, 2013, \# 2. 5-14 pp.

Vietnam beaches are covered with water, the Internet source, access mode: http://www.poedem.ru/news/151168/, date of access: 24.02.2015.

Pham, Khoi Nguyen, 2009. Foreword of the Minister of Natural Resources and Environment. In the: Viet Nam assessment report on Climate Change (VARCC). Ha Noi, Institute of Strategy and Policy on Natural Resources and Environment.127 pp.

Ryazantsev, S.V., Luk'yanets A.S. and Nguyen Canh Toan, 2012. Demographic processes in Vietnam in the context of global warming. In the: Scientific Review. Series 1: Economics and Law, Moscow. \#5. 65-72 pp.

Smarter, C., 2012 Practical Steps for Low-Carbon Living. By Seth Shulman et al. Island Press. 328 pp.

Tran, Hong Viet. Climate Change initiatives. Electronic source. Access mode: http://vietnam.um.dk/en/danida-en/climate-change-initiatives/, date of access 24.02.2015.

Labor and Employment in Russia - 2013, 2014. Statistical Yearbook. Moscow: Rosstat. 333 pp.

Hiroshi, Takagi, Miguel Esteban and Nguyen Danh Thao, 2014. Coastal Disasters and Climate Change in Vietnam. Gardners Books, Litres. 424 pp.

Ha Thi, Quynh Nga, 2014. Climate Change and Energy in Vietnam. Is the door open for civil society? [electronic source]. Access mode: http://www.fessustainability.org/en/nachhaltigkeit-und-demokratie/climate-change-and-energy-vietnam, date of access: 24.02. 2015.

Chris, Rose, 2014. Canada Urged to Prepare for 'Climate Migrants' in Warming World: New Report [electronic resource]. Access mode: http://www.desmogblog.com/2014/11/10/new-report-urges-canada-prepare-climate-migrants-warming-world-ccpa, date of access 23.02.2015. 